\section{MATTERS ARISING}

\section{Penfield's homunculus}

I was fascinated to read GD Schott's devastating, but also enlightening and at times amusing critique of the scientific value of Penfield's homunculus. ${ }^{1} \mathrm{He}$ points out some of the non-scientific associations of the word "homunculus"-for example, in modern psychology (In that remark the abused child is speaking).

I would add that a similar notion has become a part of contemporary folklore (Inside every fat man there is a thin man struggling to get out) and is reminiscent, not only of Cartesian philosophy (the ghost in the machine), but also of some basic assumptions of ear acupuncture and iridology (where the whole human body is represented by points on the lateral surface of the ear and circumscribed areas on the iris, respectively). It is one of the merits of Schott's editorial that the reader is initially puzzled by the choise of the ill-defined term "homunculus," with its multifarious associations, bu such a scrupulously scientific investigator as Penfield, but comes to realise that the scientific evidence for this concept is equally puzzling.

Underlying, but not made explicit in Schott's critique is a superficially whimsical, but highly relevant, and surprisingly intractable, philosophical puzzle, namely, how one thing can be about another thing, in this instance, how a drawing of a homunculus can be about a certain constellation of neurons - or, for that matter, how a drawing of a homunculus can be about anything at all. One answer might be that Penfield meant the homunculus to be about certain neurons (an explanation of the problem in terms of mental states), but this merely moves the scenery and leaves the problem itself centre stage. Another approach is to bring back from the very same teleology banished by Schott from the theatre of science: Penfield's mind was "designed", or had evolved, in such a way that the homunculus seemed to him to be a satisfactory representation of the results of his work on stimulation of the human cerebral cortex.

\section{JOHN CRICHTON Institute of Psychiatry, De Crespigny Park, Denmark Hill, \\ London SE5 8AF, UK}

1 Schott GD. Penfield's homunculus: a note on cerebral cartography. I Neurol Neurosurg Psychiatry 1993;56:329-33.

\section{Schott replies:}

I was interested to read Dr Crichton's comments about some of the philosophical issues raised by the homunculus concept. The representation of the human body in respect of ear acupuncture has also been illustrated, even in modern times (fig).

Philosophical ideas about the homunculus, although discussed today, were of concern many centuries ago. The term probably originated in the 15 th century, ${ }^{2}$ but has had different meanings in different eras. For instance, Paracelsus used the term

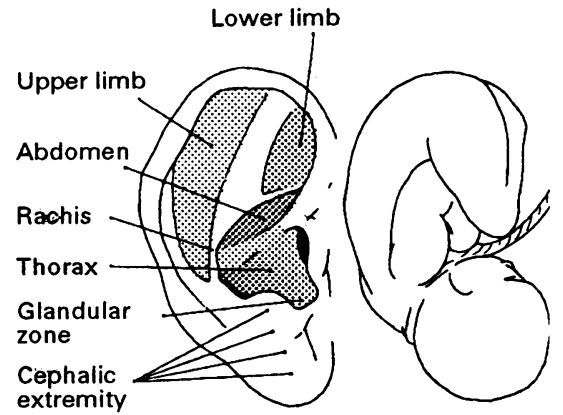

\section{BOOK REVIEWS}

All titles reviewed here are available from the BMJ Bookshop, PO Box 295, London WC1H 9TE. Prices include postage in the United Kingdom and for members of the British Forces Overseas, but overseas customers should add $£ 2$ per item for postage and packing. Payment can be made by cheque in sterling drawn on a United Kingdom bank, or by credit card (Mastercard, Visa or American Express) stating card number, expiratory date, and

to mean a fusion in man of animal and human spirits or qualities, ${ }^{3}$ a far cry from Penfield's use of the homunculus. In philosophy, as in medicine, it is important to define and illustrate what one means.

G D SCHOTT

The National Hospital for Neurology and Neurosurgery, Queen Square, London WC1N 3BG, UK

1 Nogier PFM. Treatise of auriculotherapy. Moulins-les-Metz: Maisonneuve 1972;58.

Kuhn SM (ed). Middle English Dictionary, vol 4. Ann Arbor: University of Michigan Press 1963;982.

3 Sudhoff K (ed). Paracelsus: Sämtliche Werke, vol 14, I. Munich: Oldenbourg, 1922;325.

\section{NOTICES}

The XIIth International Congress of Neuropathology will be held in Toronto, Ontario, Canada from 18-23 September 1994. This meeting will be conjoint with the American Association of Neuropathologists Annual Meeting and the Canadian Association of Neuropathologists Annual Meeting. For further information please contact Dr J J Gilbert, Victoria Hospital Research Institute, 375 South Street, London, Ontario N6A 4G5, Canada. Tel +1 519-667-6649, fax +1 519432-7367.

\section{The American Neuropsychiatric} Association will hold its Sixth Annual Meeting on July 21-23, 1994 in Newport, Rhode Island, USA. The meeting will be a joint session with the British Neuropsychiatry Association and the programme will include invited lectures, platform and poster presentations, and videotaped case demonstrations. The meeting theme is "Subcortical disease in neuropsychiatry". Information regarding this meeting and requests for abstract submission forms can be obtained from: Stephen Salloway, MD, Chairman, Scientific Programme Planning Committee, Department of Neurology, Butler Hospital, 345 Blacktone Blvd. Providence, Rhode Island 02906, USA. Tel. +1 401 455-6403; fax. $+1401455-6405$ your full name.
Surgery for Stroke. Edited by $R \quad M$ GREENHALGH and $\mathrm{L} H$ HOLLIER. (Pp 420 Illustrated; Price: $£ 70.00)$. 1993. London, WB Saunders Co. Ltd. ISBN 0-70201759-0.

The title of this multi-author book is somewhat misleading as it is concerned only with carotid surgery; intracranial surgery for haematoma is not dealt with. This being said it is an excellent production. The opening historical chapter makes one appreciate how far we have come since 1954, when carotid stenosis was treated by resecting the affected segment of artery followed by endto-end anastomosis, all carried out under hypothermia. This is followed by the usual chapters on cerebral ischaemia and on the pathophysiology or the carotid plaque. Good evidence is presented to show that the incidence of restenosis after surgery is higher in smokers but the authors simply state the facts without commenting on the currently topical, ethical issues which may arise.

Interesting chapters follow on methods of investigation, the view being expressed that conventional angiography is probably on its way out. Not that the authors believe that Duplex scanning, valuable though it is, is enough; it gives good pictures of the carotid lesion but tells nothing of the cerebral circulation as a whole. It is to magnetic resonance imaging and to computed tomographic angiography that the authors look for the future.

Most important is the section on the indications for carotid endarterectomy. Here it is made clear that you cannot simply say that endarterectomy is indicated in this or that condition; medical audit must be brought in. The surgical mortality in a particular institution must be known before a decision can be reached. This being said, endarterectomy for asymptomatic carotid lesions is recommended, provided the surgical mortality is less than 3 per cent. In TIAs, stenoses of 70 per cent or more should be removed. After a completed stroke much depends on the degree of residual disabilty; if this is not too great, endarterectomy is recommended, but only after a delay of four to six weeks. The remainder of the book is largely concerned with surgical technique, on which the present reviewer is not competent to pronounce, but, this aside, the book can be 
strongly recommended to all who are engaged in the management of people with strokes.

JOHN MARSHALL

Neuropsychiatric Disorders. By $G W$ ROBERTS, P N LEIGH and N R WEINBERGER.

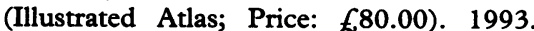
London, Mosby-Year Book Europe Ltd. ISBN 1-56375-510-6.

Neurologists and psychiatrists share common interests in a range of brain diseases, the more so as modern neuroscience is applied to the biology of neurodegenerative and functional disorders. This volume is sophisticated introduction to the major neuropsychiatric conditions, concentrating upon the dementias, selected movement disorders, epilepsy and the major psychoses. The text is succinct, but conveys the essential information required to approach the clinical features, neuropathology, concepts of aetiology and management of these conditions.

There are copious beautiful illustrations, particularly of neuropathology. Each chapter is supplemented by coloured boxes and diagrams highlighting key features and mechanisms. Those of a visual frame of mind will find much to please them. There is a limited list of references to further reading. Clinicians and scientists will find this a valuable introduction to the field, and given the lavish production the cost of $£ 80$ is not too excessive.

CD MARSDEN

Focal Peripheral Neuropathies-2nd Edition. By JOHN D STEWART. (Pp 506 Illustrated; Price: \$107.50). 1993. New York, Raven Press. ISBN 0-7817-0071-X.

Localised peripheral nerve lesions are common and, apart from some such as the carpal tunnel syndrome or Bell's palsy, frequently give rise to diagnostic difficulty. The first edition of this book, published six years ago, was a conspicuous success. The major justifications for the second edition were the increased use of imaging techniques in the diagnosis of focal neuropathies and the growing interest in peripheral nerve lesions of occupational origin. The large number of references in the first edition, which amounted to 1100 , has been doubled. John Stewart's approach is both practical and critical and is prefaced by a succinct account of the relevant experimental pathology and investigative techniques. $\mathrm{He}$ displays a healthy scepticism towards many of the silly ideas that have been advanced concerning the thoracic outlet syndrome that have led to much unnecessary surgery. This scepticism justifiably extends to the suggested participation of nerve injury in soft tissues syndrome such as tennis elbow and pyriformis syndrome. His experience, like that of the reviewer, is that many of the musicians referred with possible peripheral nerve lesions turn out to have focal dystonias.

The book is comprehensive, but the reviewer was surprised not to be able to find coverage of the focal hypertrophic demyelinating neuropathy as encountered in the brachial plexus and at times in limb nerves, or of the enigmatic condition focal hypertrophic neurofibrosis, apart from a brief ref- erence to the tibial nerve. These conditions are frequently misdiagnosed and can be mistaken for motor neuron disease or peripheral nerve tumours. The inflammatory demyelinating form may respond well to treatment.

Reference to hereditary liability to pressure palsies is made, but the book obviously went to press before the recent intriguing discovery that this disorder is usually related to a segmental deletion on chromosome 17 , affecting the gene for peripheral myelin protein 22. The presence of this condition in a variety of unexpected ways is now becoming evident.

Dr Stewart's book should appeal to a wide audience amongst neurologists, neurosurgeons, orthopaedic surgeons and, not least, those interested in medicolegal work in which peripheral nerve injury tends to feature quite prominently.

PK THOMAS

Tension-type Headache: Classification, Mechanisms, and Treatment (Frontiers in Headache Research, Vol 3). Edited by JES OLESEN and JEAN SCHOENEN. (Pp 293; Price: \$120.00). New York, Raven Press. 1993. ISBN 0-7817-00701.

The first chapter discloses a major weakness of the book, the problem-essential to all subsequent contributions - of diagnosis. Olesen (chapter 1) writes, "It is not the purpose of this chapter to give a detailed discussion of the daily routine diagnosis of tension-type headache". But he lists the operational diagnostic criteria from the International Headache Society (IHS) Classification. These are mightily criticized by Ninan Mathew (chapter 3): "Although the IHS headache classification has greatly enhanced the precision of diagnosis of migraine and cluster headaches, its application in chronic headache has been less than satisfactory"-an American gentlemanly understatement. Mathew lists these deficiencies and provides a new classification including transformed migraine, tension headache evolving to migraine (drug and non-drug induced), and daily persistent headache. $30 \%$ of his patients have intractable headache due to "a persistent neurobehavioural disorder".

"The differential diagnosis between tension-type headache and migraine is not always easy." Solomon points out "the unacceptably low sensitivity and specificity for the diagnosis of tension-type headache" from questionnaires completed by patients, states the differing views on the relationship, and lack of relationship, between tension-type headache and migraine, yet offers no clarification on how to achieve a correct diagnosis. Are we in the realm of classifiers, codifiers, or the diagnostically destitute?

Section II deals with the structural and functional basis of muscle nociception, pain perception in healthy volunteers including the effect of sex, mood and circadian rhythms. Patrick Wall concludes the section with a thought provoking summary.

Section III on Pathology, Pharmacology and Biochemistry attributes fibromyalgia to muscle microlesions (not demonstrated) provoked by over and under activity, and in another chapter experimentally induced muscle pain induced by ischaemic work, injection of nonspecific algogenic substances as well as specific endogenous agents- $5 \mathrm{HT}$, bradykinin, substance $P$ and CGRP. A review of 5HT, platelet enzymes, methionine-enkephalin, noradrenaline and other biogenic enzymes, ends with the usual plea for more research. Transcranial Doppler studies indicate an instability of the cerebral circulation, and magnesium, the latest fashionable substance, gets a mention.

Section IV on central mechanisms of tension-type headache concludes on the basis of decreased plasma and CSF endorphins and EMG studies that a central pathogenesis causes tension headache. However Section V on the basis of muscle tenderness and EMG findings provides evidence of a peripheral component.

The final therapeutic section (VI) has papers on relaxation/biofeedback therapy, stress management, analgesic abuse, psychotherapy, analgesics, muscle relaxants and psychotropic drugs, and ends with a critical summary by Mathew.

This frontier of headache research seems bordered by muddy waters. How can these problems be clarified? Perhaps a start could be made by removing doubtful entities"chronified migraine" and "mixed headache". But reading this book one can detect a great deal of occupational therapy for research assistants, limited treatment for patients and few new ideas - reflecting the state of the art and current ignorance on tension (-type) headache. This conference threw little light on the topic.

JN BLAU

Stroke: Populations, Cohorts, and Clinical Trials. Edited by JACK $P$ WHISNANT. (Pp 263; Price: $£ 45.00$ ). 1993. Oxford, Butterworth-Heinemann. ISBN 07506-0574-X

In this, the 12th of Butterworth Heinemann's International Medical Reviews of neurology Dr J P Whisnant from the Mayo Clinic edits papers from a number of clinicians and statisticians from the US, Japan and Europe on topics related to clinical research in stroke disease. The book is a strange mixture of critiques of clinical measurement and of statistical assessment in the field of clinical trials. Some of the chapters, such as that on 'Stroke Morbidity', provide an interesting and useful resumé of recent trials and a summary of current knowledge. Others, such as that on 'Attributable Risk', are predominantly a mathematical treatise on statistical methods. It is perhaps surprising that in a clinical sphere which has been so exposed to metaanalyses no British author has been involved and no critique is provided of the technique of meta-analysis and its use in stroke disease.

The individual papers are well presented and the explanations of statistical fact and eponym are clear. Most of the papers relate to trials of stroke prevention and to epidemiology and only in the final chapter are there considerations of primary prevention trials, studies of rehabilitation and consideration of the newest therapies. Nonetheless the volume as a whole is useful to those in clinical neurology and essential reading to anyone planning on setting up clinical trials in the field of stroke research where its comprehensive reviews and severe criticisms of statistical methods will be of considerable help.

DAVID BATES 